\title{
SAPHO syndrome associated with a digestive disorder in a ten-year-old girl: Diagnostic difficulties
}

\author{
Bérénice Dégboé1, Gloria Nouhoumon', Christabelle Nguessie', Fabrice Akpadjan', \\ Nadège Agbéssi ${ }^{2}$, Christiane Koudoukpo ${ }^{2}$, Zavier Zomalheto ${ }^{3}$, Jean Sèhonou ${ }^{4}$, \\ Hugues Adégbidi', Félix Atadokpèdé ${ }^{1}$
}

\begin{abstract}
${ }^{1}$ Department of Dermatology Venereology, National Teaching Hospital Center Hubert Koutoukou Maga of Cotonou, Faculty of Health Sciences - University of Abomey-Calavi, Benin, ${ }^{2}$ Department of Dermatology Venereology, Departmental Teaching Hospital Center Borgou-Alibori, Faculty of Medicine-University of Parakou, Benin, ${ }^{3}$ Department of Rheumatology, National Teaching Hospital Center Hubert Koutoukou Maga of Cotonou, Faculty of Health Sciences - University of Abomey-Calavi, Benin, ${ }^{4}$ Department of Hepato-Gastroenterology, National Teaching Hospital Center Hubert Koutoukou Maga of Cotonou, Faculty of Health Sciences - University of Abomey-Calavi, Benin
\end{abstract}

Corresponding author: Bérénice Dégboé, MD, E-mail: kebdegboe@yahoo.fr

\begin{abstract}
SAPHO syndrome (acronym for synovitis, acne, pustulosis, hyperostosis, osteitis) is a rare dermato-rheumatic entity usually observed in young adults. The clinical manifestations are proteinaceous and without specificity at the origin of inflammatory diseases of the intestine. Our clinical case is that of a ten-year-old girl who presented with chronic and recurrent osteomyelitis of the pelvic limbs on a febrile background, followed by persistent and recurrent pustular lesions. During the same period, because of an acute abdominal pain syndrome accompanied by fever, a biological inflammatory syndrome, and predominantly neutrophilic hyperleukocytosis, laparotomy was performed and no lesions were found. She subsequently presented with intermittent and recurrent spasmodic abdominal pain. In view of these various symptoms, a multidisciplinary consultation concluded that the patient had SAPHO syndrome associated with a digestive disorder, possibly Crohn's disease. Our clinical case illustrates the diagnostic difficulties of SAPHO syndrome.
\end{abstract}

Keywords: SAPHO syndrome; Chronic recurrent osteomyelitis in children, Inflammatory bowel disease, Pustulosis, Benin

\section{INTRODUCTION}

SAPHO syndrome (acronym for synovitis, acne, pustulosis, hyperostosis, osteitis) is an auto-inflammatory disease characterized by neutrophilic damage, which may affect the skin, bones, and joints [1,2]. Having a low incidence (1-4/10.000 individuals), it is usually observed in young adults. Rheumatologic involvement is most often axial and the most frequently reported dermatological manifestations are palmoplantar pustulosis and severe acne [1-4].

These very diverse and nonspecific clinical manifestations often lead to diagnostic delays and sometimes expose patients to numerous invasive explorations and inappropriate and harmful therapies $[1,2,5]$.

SAPHO syndrome may be associated with other inflammatory diseases, including cryptogenetic inflammatory bowel disease (IBD) [5-7]. Herein, we report a case of SAPHO syndrome associated with digestive involvement, possibly Crohn's disease, in a ten-year-old girl after almost three years of diagnostic wandering.

\section{CASE REPORT}

A ten-year-old girl was referred to us for the management of pustular, painful, and itchy skin lesions that had been

\footnotetext{
How to cite this article: Dégboé B, Nouhoumon G, Nguessie C, Akpadjan F, Agbéssi N, Koudoukpo C, Zomalheto Z, Sèhonou J, Adégbidi H, Atadokpèdé F. SAPHO syndrome associated with a digestive disorder in a ten-year-old girl: Diagnostic difficulties. Our Dermatol Online. 2022;13(1):57-61.

Submission: 21.09.2021; Acceptance: 23.11.2021

DOI: 10.7241 /ourd.20221.13
} 
progressing for two years with attenuation periods. A cytobacteriological examination of the pus from the skin lesions allowed us to isolate initially Staphylococcus aureus and then Staphylococcus lugdunensis, which motivated an antibiotic therapy adapted to the antibiogram, yet without success.

During the interrogation, it was noted that suppurative arthritis of the left ankle, treated with several antibiotics and resulting in a slight improvement, occurred eight months before the appearance of the pustules. This episode was followed two weeks later by an acute abdominal pain syndrome on a febrile background. Paraclinical workup at that time revealed a biological inflammatory syndrome with C-reactive protein (CRP) at $56 \mathrm{mg} / \mathrm{L}$, an accelerated erythrocyte sedimentation rate (ESR) at $53 \mathrm{~mm}$, and hyperleukocytosis at $10.8 \mathrm{~g} / \mathrm{L}$; a Widal test confirmed a previous anti-typhoid vaccination. The patient underwent exploratory laparotomy, which returned inconclusive.

The evolution was marked by several episodes of febrile osteomyelitis of the pelvic limbs chronically evolving with moderate functional impotence. X-rays and bone scans of the lower limbs revealed foci of pandiaphyseal osteo-condensation (Fig. 1); an angioscan of the same region returned normal. Bone biopsy was not performed. Repeated treatment with antibiotics and anti-inflammatory drugs resulted in a slight improvement between episodes.

A physical examination of the patient revealed a slightly altered general state, no fever, and signs of moderate acute malnutrition $\left(B M I=14.79 \mathrm{~kg} / \mathrm{m}^{2}\right)$. The left anterior thoracic wall and the posterior faces of the thighs and legs were the sites of grossly oval ulcerations $(n=4)$, some of which were budding, with a flesh-red or fibrino-purulent base, with regular, unstuck edges and insensitive to protected palpation (Figs. 2 and 3). Erosive and crusted plaques were also found on the anterior faces of both legs (Fig. 4). The folds, mucous membranes, and skin adnexa were unharmed. On the osteoarticular side, there was a static anomaly with a limping gait, hyperostosis of the right leg (Fig. 5), and a slight sensitivity to pressure of the long bones of the right leg. There was no adenopathy. Examination of the other systems was normal except for the laparotomy scar.

The results of biological tests performed confirmed the abnormalities observed in the clinical history. HIV serology was negative.
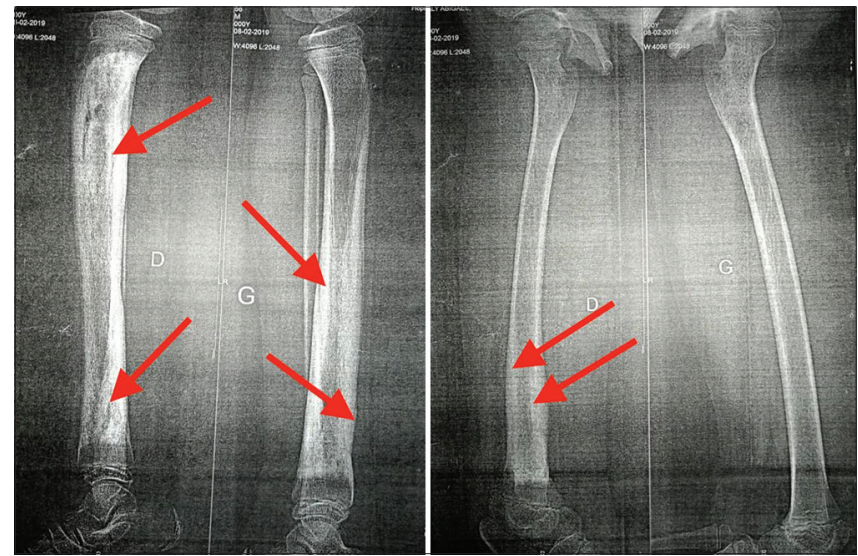

Figure 1: X-ray of the two bones of the legs showing total pandiaphyseal osteosclerosis of the shins on the right leg and the lower half on the left leg (red arrows).

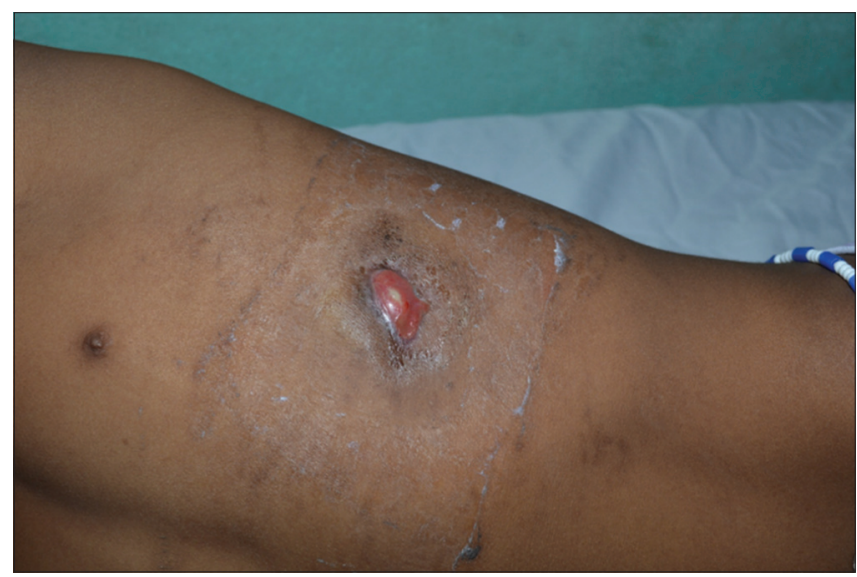

Figure 2: X-ray of the femur showing an extension of the osteosclerosis to the lower third of the right femur (red arrows).

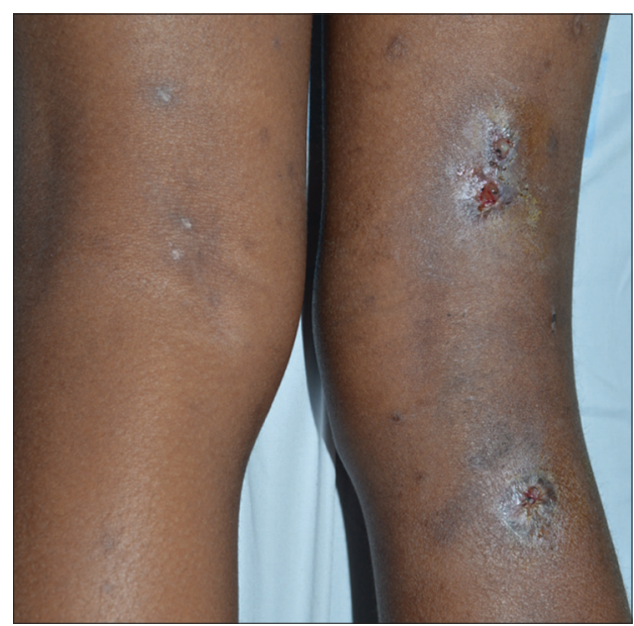

Figure 3: Oval, budding ulceration of the left anterolateral chest wall.

In view of the osteoarticular disorders, digestive symptoms, and dermatological lesions, a multidisciplinary consultation meeting was held and the diagnosis of SAPHO associated with possible Crohn's disease was 


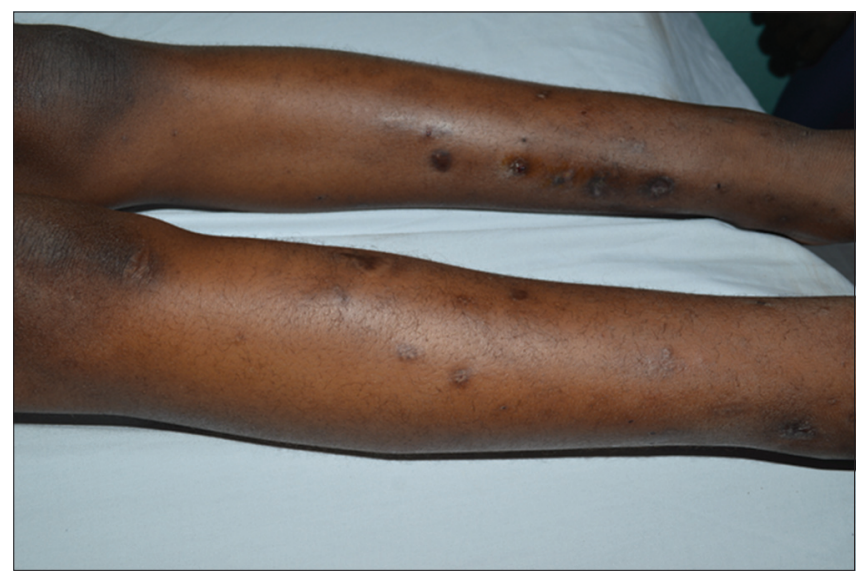

Figure 4: Oval ulceration with a fibrino-purulent base on the posterior surface of the right thigh and leg.

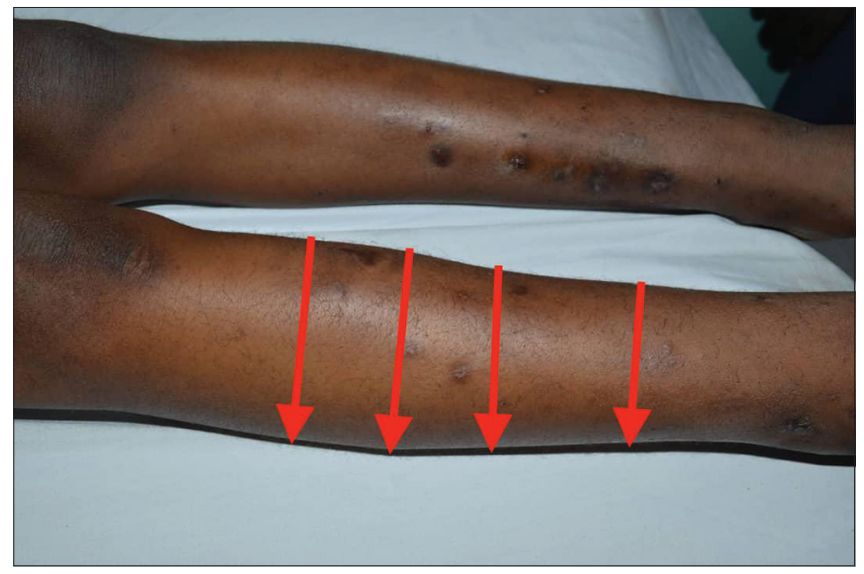

Figure 5: Crusty erosions on the anterior face of the legs and hyperostosis of the right leg (red arrows).

retained. The planned digestive explorations could not be performed due to lack of financial means. A local treatment with povidone-iodine was initiated in combination with colchicine at a dose of $1 \mathrm{mg} / \mathrm{kg}$ per day. The subsequent evolution under treatment could not be assessed because the patient discontinued follow-up.

\section{DISCUSSION}

SAPHO syndrome is a rare and poorly known dermato-rheumatologic entity. It seems to be even rarer in children and the average age at the time of the first symptoms falls between 30 and 40 years of age $[1,2,4]$. Our patient had her first symptoms at the age of eight years.

Bone manifestations are the cornerstone of the diagnosis. They are axial in adults and peripheral multifocal in children with classic CMRO (chronic multifocal recurrent osteomyelitis) [4,8-11]. The dermatologic component may precede the first signs of rheumatism by years or, on the contrary, may occur extremely late $[3,4,12]$. It may even be absent throughout the course of the disease, yet this does not prevent the diagnosis from being based on purely rheumatologic arguments $[1,12,13]$. The most commonly described skin disorders are palmoplantar pustulosis in approx. 60\% of cases and severe acne in approx. $20 \%$ of cases; psoriasis, Verneuil's disease, pyoderma gangrenosum, and Sweet's syndrome are more rarely reported $[1,3,4,12]$.

The non-specificity and great clinical diversity of SAPHO syndrome led to the development of diagnostic criteria by Benhamou, then Kahn. [12,14]. However, it should be noted that these criteria have not been validated by consensus as they still do not correspond to clinical situations observed. The manifestations of the disease vary considerably from one individual to another. Moreover, these different signs do not appear simultaneously $[1,12]$. This is often at the origin of diagnostic error and sometimes at the origin of inappropriate therapy. Zimmermann et al. reported an average duration of nine years between the first symptoms and diagnosis, while Roderick et al. found an average of fifteen months between the onset of symptoms and the time of diagnosis in children $[1,10]$. This was the case in our patient, who presented with pustular lesions of the body and multifocal bone involvement of the long bones and whose diagnosis was reached two years and eight months from the first signs.

Another striking fact is that our patient had a suspicious symptomatology of associated inflammatory bowel disease (IBD). This association is described and accounted for 5-10\% of all cases of SAPHO [15-17]. The evolution of the two pathologies could be independent: SAPHO may precede or occur several years after IBD. In only $10 \%$ of cases, the onset is simultaneous, as in the case of our patient $[5,7,8,12]$. The abdominal pain of the surgical type at the beginning, evolving into an intermittent mode thereafter, the observed undernutrition, and especially the absence of rectal bleeding in our case suggest an association with Crohn's disease. In a meta-analysis by Juan et al., the association of SAPHO with Crohn's disease remains the most frequent, $69 \%$ against $31 \%$ for ulcerative colitis $[5,8]$.

The pathogenesis of these two diseases remains poorly understood. Three theories have been suggested regarding SAPHO syndrome: the genetic theory suspected in view of the presence of familial forms, certain HLA histocompatibility genes (HLA-A26, HLA-B27, 
HLA-B39, HLA-B61) and other predisposition genes located on chromosomes 1 and 18 [1,2,9,12,18-20]; the infectious or post-infectious theory incriminating Cutibacterium acnes found in $67 \%$ of bone biopsy samples $[14,19]$; the immunologic theory based on the evidence of a significant secretion of various pro-inflammatory cytokines and TNF-alpha $[1,2,4]$.

As for Crohn's disease, the involvement of three factors remains the pathogenic basis: genetic factors according to Naves et al. [8]; environmental factors, especially tobacco and appendectomy [21] and intestinal dysbiosis [22,23]; a common genetic ground linked to the HLAB27 group [24] and intestinal dysbiosis [2] could, therefore, explain this morbid association between SAPHO and IBD.

There is no codified treatment for SAPHO syndrome, especially in association with IBD. Management must be multidisciplinary (medical, surgical, and psychological). The efficacy of anti-inflammatory drugs, sulfonamides, analgesics, immunosuppressants, and antibiotics previously used is inconsistent $[1,4,25,26]$. Therapeutic perspectives aim at the use of bisphosphonates, especially in children, and anti-TNF biotherapies [9,11,27-29] with apparent efficacy and good tolerance.

However, the prognosis is not life-threatening in patients with SAPHO. In some cases, a severe functional handicap in walking and a significant psychological impact are observed $[1,25,30]$.

\section{CONCLUSION}

SAPHO syndrome is rare, particularly in children, and often manifests itself as a peripheral rheumatologic disorder. Its diagnosis is always difficult because of the nonspecific clinical manifestations. Skin involvement is most often manifested by inflammatory dermatosis, which is typically resistant to conventional treatment.

In rare cases, SAPHO syndrome may be associated with cryptogenic inflammatory bowel disease. It also poses a therapeutic challenge as its pathogenesis is currently a puzzle with several pieces still missing. A better knowledge of this pathogenesis remains the present challenge and it is even greater in cases of association with other auto-inflammatory diseases.

\section{ACKNOWLEDGMENT}

We would like to thank the patient and their parents for compliance in the study.

(c) Our Dermatol Online 1.2022

\section{CONSENT}

The examination of the patient was conducted according to the principles of the Declaration of Helsinki.

The authors certify that they have obtained all appropriate patient consent forms, in which the patients gave their consent for images and other clinical information to be included in the journal. The patients understand that their names and initials will not be published and due effort will be made to conceal their identity, but that anonymity cannot be guaranteed.

\section{REFERENCES}

1. Zimmermann P, Curtis N. Synovitis, acne, pustulosis, hyperostosis, and osteitis (SAPHO) syndrome: A challenging diagnosis not to be missed. J Infect. 2016;72:S106-14.

2. Huhn CK, Schauer F, Schempp CM, Venhoff N, Finze S. Skin inflammation associated with arthritis, synovitis and enthesitis. Part 1: Psoriatic arthritis, SAPHO syndrome, Still's disease, Behçet's disease. J Dtsch Dermatol Ges. 2019;17:43-64.

3. Li Y, Li C, Wu N, Li F, Wu Z, Sun W, et al. Demographic, clinical, and scintigraphic comparison of patients affected by palmoplantar pustulosis and severe acne: A retrospective study. Clin Rheumatol. 2020;39:1989-96.

4. Nguyen MT, Borchers A, Selmi C, Naguwa SM, Cheema G, Gershwin ME. The SAPHO syndrome. Semin Arthritis Rheum. 2012;42:254-65.

5. Amano H, Matsuda R, Shibata T, Takahashi D, Suzuki S. Paradoxical SAPHO syndrome observed during anti-TNF therapy for Crohn's disease. Biologics. 2017;11:65-9.

6. Schaeverbeke T. Truchetet M.E. Richez C. Rôle des facteurs d'environnement dans les spondyloarthrites. Rev Rhumat Monograph. 2015;82:3-6.

7. van Ommen C, Dehoorne J, De Baets F, Vande Velde S, Van Winckel M, Van Biervliet S. A case of chronic recurrent multifocal osteomyelitis associated with Crohn's disease. Acta Gastroenterol Belg. 2015;78:240-3.

8. Naves JE, Cabré E, Manosa M, Grados D, Olivé A, Domènech E. A systematic review of SAPHO syndrome and inflammatory bowel disease association. Dig Dis Sci. 2013;58:2138-47.

9. Kyriazi N, Papamerkouriou Y-M, Maritsi D, Dargara Sr. MA, Michelarakis J. Pediatric synovitis, acne, pustulosis, hyperostosis, osteitis (SAPHO) syndrome: Diagnostic challenges and treatment approach. Cureus. 2020;12:e7595.

10. Roderick MR, Shah R, Rogers V, Finn A, Ramanan AV. Chronic recurrent multifocal osteomyelitis (CRMO): Advancing the diagnosis. Pediatr Rheumatol Online J. 2016;14:47.

11. Świdrowska-Jaros J, Smolewska E. A complicated path to the CRMO diagnosis: Case of a 9 years old girl whose story comes full circle. BMC Musculoskelet Disord. 2019;20:392.

12. Cianci F, Zoli A, Gremese E, Ferraccioli G. Clinical heterogeneity of SAPHO syndrome: Challenging diagnose and treatment. Clin Rheumatol. 2017;36:2151-8.

13. Duan N, Chen X, Liu Y, Wang J, Wang Z. Multimodal imaging findings of SAPHO syndrome with no skin lesions: A report of three cases and review of the literature. Exp Ther Med. 2016;12:2665-70.

14. Kahn MF, Khan MA. The SAPHO syndrome. Baillieres Clin Rheumatol. 1994;8:3333-62.

15. Marc E, Lecluyse K, Chioccioli C, Marie B, Emmanuelle C, Pierre L. Maladie de Crohn et syndrome SAPHO au cours d'un traitement à l'infliximab. Gastroenterol Clin Biol. 2007;31:607-10.

16. Keith S, Cathérine L. Syndrome SAPHO chez un adulte atteint de colite ulcéreuse répondeur au pamidronate intraveineux. Revue du 
rhumatisme. 2010;77:206-7.

17. Morbach H, Dick A, Beck C, Stenzel M, Muller HK, Raab P. Association of chronic non-bacterial osteomyelitis with Crohn's disease but not with CARD15 gene variants. Rheumatol Int. 2010;30:617-21.

18. Yeon HB, Lindor NM, Seidman JG, Seidman CE. Pyogenic arthritis, pyoderma gangrenosum, and acne syndrome maps to chromosome 15q. Am J Hum Genet. 2000;66:1443-8.

19. Zimmermann P, Curtis N. The role of Cutibacterium acnes in auto-inflammatory bone disorders. Eur J Pediatr. 2019;178:89-95.

20. Assmann G, Kueck O, Kirchhoff T. Efficacy of antibiotic therapy for SAPHO syndrome is lost after its discontinuation: Interventional study. Arthritis Res Ther. 2009;11:R140.

21. Tunay K, Franck H, Hasan M, Laurent PB. Physiopathologie des maladies inflammatoires chroniques de l'intestin. HEGEL. 2016;2:119-29.

22. Manichanh C, Rigottier L, Bonnaud E, et al. Reduced diversity of faecal microbiota in Crohn's disease revelated by a metagenomic approach. Gut. 2006;55:205-11.

23. Baugart M, Dogan D, Rishniw M, Weitzman G, Bosworth B, Yantiss R, et al. Culture independent analysis of ileal mucosa reveals a selective increase in invasive Escherichia coli of novel phylogeny relative to depletion of Clostridiales in Crohn's disease involving the ileum. ISME J. 2007;1:403-18.

24. Kanh MF, Bouchon JP, Chamot AM, Palazzo E. Syndrome SAPHO, une maladie extra-digestive rare de la maladie de Crohn. Gastroenterol Clin Biol. 1998;22:p240.
25. Liu S, Tang M, Cao Y, Li C. Synovitis, acne, pustulosis, hyperostosis, and osteitis syndrome: review and update. Ther Adv Musculoskelet Dis. 2020;12:1-14.

26. Chamot AM, Kahn MF. SAPHO syndrome. Rheumatol. 1994;53:234-42.

27. Kerrison C, Davidson JE, Cleary AG, Beresford MW. Pamidronate in the treatment of childhood SAPHO syndrome. Rheumatology. 2004;43:1246-51.

28. Wagner AD, Andresen J, Jendro MC. Sustained response to tumor necrosis factor alpha-blocking agents in two patients with SAPHO syndrome. Arthritis Rheumat. 2002;46:1965-68.

29. Hofmann SR, Kapplusch F, Girschick HJ, Morbach H, Pablik J, Ferguson PJ, et al. Chronic recurrent multifocal osteomyelitis (CRMO): Presentation, pathogenesis, and treatment. Curr Osteoporos Rep. 2017;15:542-54.

30. Schilling F, Coerdt W, Eckardt A, Full H, Hospach T, Kessler S et al. Pelvic Type of Chronic Recurrent Multifocal Osteomyelitis (CRMO) in children and adolescents: Clinical aspects, radiological and pathological findings in 11 cases. Klin Pädiatr. 2001;213:277-84.

Copyright by Bérénice Dégboé, et al. This is an open-access article distributed under the terms of the Creative Commons Attribution License, which permits unrestricted use, distribution, and reproduction in any medium, provided the original author and source are credited. Source of Support: Nil, Conflict of Interest: None declared. 